\title{
The case of the top Spanish YouTubers \\ Emerging media subjects and discourse practices in the new media ecology
}

\author{
Carlos A. Scolari \\ Universitat Pompeu Fabra \\ Department of Communication \\ Room 52.829 \\ c/ Roc Boronat 138 \\ 08018 Barcelona \\ SPAIN \\ Damián Fraticelli \\ Universidad de Buenos Aires \\ Department of Communication \\ c/Santiago del Estero 1029 \\ C1075AAU Ciudad Autónoma de Buenos Aires \\ ARGENTINA
}

\begin{abstract}
The objective of this article is to propose a first exploratory analysis of the Spanish YouTubers' main productions and practices. Following the description of the emergence of YouTube in the context of media ecology, the article presents a general overview of the top ten Spanish YouTubers' production based on quantitative data. The study continues with a semiotic/discursive analysis of their audio-visual production's main distinctive traits. As traditional television is imitating nowadays these new media expressions, this article also addresses the aesthetics and grammar of Yutubers, a TV program produced by Comedy Central that simulates the Spanish YouTubers channels' aesthetics and language. The analysis concludes with a discussion on the study's findings and a series of questions about these new media subjects.
\end{abstract}

\section{Keywords}

YouTube, YouTubers, vBloggers, media ecology, media evolution, hypertelevision, simulation, social media 


\section{Publication}

Convergence: The International Journal of Research into New Media Technologies 120

Online First: First Published July 27, 2017

DOI: $10.1177 / 1354856517721807$

Copyright: The Author(s) 2017

Reprints and permission: sagepub.co.uk/journalsPermissions.nav

\section{Corresponding authors:}

Carlos A Scolari: carlosalberto.scolari@upf.edu

Damián Fraticelli: damianfraticelli@yahoo.com 
The deep transformations that media ecology has gone through the last two decades could be synthesized as the passing from a broadcast-centered to a network-centered system. In the specific case of audio-visual media, Kompare (2002) defined this transformation as the transition from flow television -one in which channels tried to keep their audiences around from program to program (Williams, 1974)- to filetelevision -based on accessibility, mobility, and on-demand consumption. The filetelevision paradigm 'is advancing on television screens all over the world, forcing the flow industries to adjust their business practices' (Kompare, 2002: 7). The arrival of YouTube and similar on-demand video platforms simply accelerated this transition. In this context, the emergence of new media subjects such as YouTubers appears as a hybrid process characterized by remediations, simulations and, as Jenkins (2006a) put it, by the convergence and collision between old and new media.

The analysis of a platform such as YouTube presents the opportunity to outline the different tensions and key issues within contemporary media ecology, for example the emergence of 'new' media subjects or the attempts to adapt on behalf of the 'old' media. The premise behind the present research is the following: the deep transformation media ecosystem is undergoing is leaving 'footprints' on the surface of media texts, so the analysis should start with media texts and move towards media processes. The combination of a general media ecologic framework with a set of analytical categories from semiotics and discourse analysis shall be helpful for the development of such research. Semiotics and discourse analysis have a long tradition in the studying of audio-visual textualities like cinema or television (Casetti, 1983; Casetti and Di Chio, 1998; Eco, 1985), genre (Bakhtin, 1986), and media discourse strategies (Carlón, 2006; 2012; 2013; Verón, 1983,1985, 2004).

The present analysis of the Spanish YouTubers should be considered an introductory exploration of a group of emerging new media subjects. The videos studied were selected from the channels of the top ten Spanish YouTubers. The textual corpus is conformed by the top five videos of each YouTuber based on the following categories: highest rating, number of comments and number of views (total: $\mathrm{n}$. 150 videos). Three issues were considered when studying the productions of these new media subjects:

- What kind of enunciation strategies are the top Spanish YouTubers using?

- Which enunciative contracts are they proposing their viewers? 
- What genres can be identified in the top Spanish YouTubers' production?

As to the analysis of adaptation processes by traditional media, the research focused on a Spanish TV show that reproduces the style of the YouTubers' broadcasts. In this case the question that structured the research was:

- How is traditional television -in this case, the Spanish TV show Yutuberssimulating the style of the YouTubers' videos?

Section 1 presents a short introduction to YouTube as an emerging platform in the new media ecology and justifies the pertinence of media ecology as a theoretical framework for understanding media emergence and adaptation processes. This section also addresses why the analysis of a traditional TV show may be useful for the detection of adaptation attempts by 'old' media. The second section describes the YouTubers as new media subjects and introduces in a simplified way the main semiotic and discursive analytical categories applied to the different videos; this section concludes with an identikit of the top Spanish YouTubers based on quantitative data. Section 3 presents the analysis of the YouTubers' discourse focusing on the contact and emotive enunciation, genre, and enunciative contracts. Finally, Section 4 deals with Yutubers, the TV show that remediates the styles and grammar of the YouTubers' channels. The article concludes with a synthesis of the findings and a series of orientations for future researchers in this field.

\section{THE EMERGENCE OF A NEW MEDIA PLATFORM}

YouTube was officially launched in June 2005 by three former PayPal employees. Thanks to a simple interface that allows the user to upload, publish and watch streaming videos, YouTube conquered in a few months' time the favour of thousands of users. As an aggregator of content but not a content producer itself, YouTube did not threaten directly the logic of commercial broadcasting. After a few years' time YouTube's original by-line -'Your Digital Video Repository'- changed into the cooler 'Broadcast Yourself', as traditional media soon discovered 'the new thing' and kept it within their radars. The rest of the story is well-known: in October 2006 Google acquired YouTube for US\$ 1.65 billion dollars, and in a few years it got transformed into a broadcast platform, a media archive and a social network (Burgess and Green, 2009: pos. 194). Van Dijck described YouTube's evolution as follows: 
YouTube did not really invent video sharing as a socio-technological practice, and neither did it revolutionize broadcast technology. Contrary to public image, Google pushed professional content at an early stage, and its innovative online strategies soon merged with conventional broadcast tactics; and, last but not least, YouTube's users were anything but complacent dudes (2013: 111).

According to Burgess and Green (2009) it is not always easy to make sense out of YouTube:

Even more than television, [YouTube] is a particularly unstable object of study, marked by dynamic change (both in terms of videos and organization), a diversity of content (which moves with a different rhythm to television but likewise flows through, and often disappears from, the service), and a similar quotidian frequency, or 'everydayness' (Burgess and Green, 2009, pos. 206).

The emergence of YouTube as a media platform reformulated a series of polarities, for example commercial interests versus public good (Van Dijck, 2013; Cunningham, Craig, and Silver, 2016; Jenkins 2006a; Jenkins, Ito and Boyd, 2016), professional production versus amateur content creation (Jenkins, 1992, 2006b; Hellekson, and Busse, 2006; Burgess and Green, 2009; Lange, 2008, 2011; Aranda, Sánchez-Navarro and Roig, 2013), public versus private behaviour (Gal, 2002; Lange, 2008), intermediation versus disintermediation (Houle, 2007; Lobato, 2016; Vonderau, 2016), and memory preservation versus experiential communication (Lange, 2011).

Today, YouTube is a major and diversified player in the contemporary media ecology, expanding well beyond amateur video-sharing and undergoing the creation of original content, video rentals and major music licensing deals (Cunningham and Silver, 2013). According to Burgess (2014), as the platform is starting to address a much broader range of users,

[...] their invitations to these new participants are becoming more audiencecentred, potentially working to dissolve the tension between author- and audience-centric versions of the user that were so culturally generative of new genres, forms and practices at earlier phases (Burgess, 2014: 283-84). 
As YouTube is still going through an 'interpretative flexible' stage of its evolution (Van Dijck, 2013) -the technology is still open to new recombinations, remediations and mutations-, vloggers or YouTubers, as we will call them along this article, are situated at the centre of those tensions and processes.

\subsection{YouTube from the perspective of media ecology}

Media ecologists have developed a holistic approach in their study of emerging media. Such approach integrates the study of the evolution of media with the socioeconomic processes from that particular historical moment. An example of this is the study of the parallel development of railroads and telegraphy in the nineteenth century (Innis, 2003). In Understanding Media, McLuhan (2003) noted another supplementary aspect to this: 'media interact among themselves. Radio changed the form of the news story as much as it altered the film image in the talkies. TV caused drastic changes in radio programming and in the form of the thing or documentary novel' (78). McLuhan summarized this concept in one of his famous aphorisms: 'No medium has its meaning or existence alone, but only in constant interplay with other media' (2003: 43). It could be said that in the beginning of the 21 st century, the old 'media species' (radio, cinema, television, books, etc.) have to compete with the new ones (YouTube, Twitter, Facebook, mobile devices, etc.) and, at the same time, adapt and adopt traits from the new interactive environment in order to survive (Scolari, 2012, 2013).

The media ecology metaphor is at the centre of many researchers' analysis. Using a perspective that combines political economy and actor-network theory, Van Dijck (2013) considers YouTube and platforms alike such as Facebook as 'microsystems' that, combined, constitute the 'ecosystem of connective media' (21).

Each microsystem is sensitive to changes in other parts of the ecosystem: if Facebook changes its interface settings, Google reacts by tweaking its artillery of platforms; if participation in Wikipedia should wane, Google's algorithmic remedies could work wonders. It is important to map convolutions in this first format stage of connective media's growth because it may teach us about current and future distribution of powers (2013: 21). 
This idea -media are not alone, they can only be understood as parts of an interconnected ecology- is very useful to understand the relation between YouTube and traditional television. According to Van Dijck, if we look at much of YouTube's content, it is hard to observe any distinction between typical YouTube content and broadcast content because of mutual imitation: 'YouTube tried to become more like television, while television increasingly adopted features from YouTube' (121).

It could be said that contemporary audio-visual production subjected its aesthetics and content to evolution in order to satisfy the desires of a new generation of viewers formed in hypertextual experience. This phenomenon has been defined as 'hypertelevision'. What's hypertelevision? It is television remediating (Bolter and Grusin, 1999) 'new' interactive media. In this period of transition, 'old' media like television must adapt to the new media ecology. How does television adapt? It does so by adopting traits of the new interactive media and simulating digital interactions on screen. Hypertelevision is addressing viewers with an elevated expertise in fragmented textualities and advanced skills in navigating interactive environments. In this context, contemporary television must evolve its aesthetics and contents to satisfy the desires of a new generation of viewers formed in hypertextual experiences. Hypertelevision shows a long series of traits, including screen fragmentation, the acceleration of rhythm, an endless intertextuality, the rupture of narrative linearity, and the multiplication of characters and narrative programs (Scolari, 2009: 41). This short reflection on how old television is simulating YouTube's content will be reprised in the analysis of the Yutubers TV show (see Section 4).

Why analyse a TV show within an investigation focused on YouTubers? Because the analysis of the Spanish TV show Yutubers introduces a good example of 'old media' simulating 'new media'. The existence of the Yutubers TV show should not be considered an extraordinary fact. As Manovich -inspired by De Certeau's The Practice of Everyday Life- put it, the companies are developing 'strategies that mimic people's tactics of bricolage, reassembly, and remix. The logic of tactics has now become the logic of strategies' (Manovich, 2009: 324). Taking into account how media has evolved, it is almost a 'natural' shift: if traditional media wants to survive, it has to adapt to the new media ecology. Therefore, an old medium like television must adopt traits of the new media. This is the only way it can reach youngest audiences and establish a 
'watching contract' with them. In this sense, Yutubers should be considered an example of hypertelevision, that is, television simulating new interactive media.

\section{YOUTUBERS AS A RESEARCH OBJECT}

\subsection{The new media subject: YouTubers}

YouTube's content comes from different sources (mainstream media, fan communities, amateurs, professionals, etc.). It has developed its 'own, internal system of celebrity based on and reflecting values that don't necessarily match up neatly with those of the dominant media' (Burgess and Green, 2009, pos. 506). The platform has created its own stars, advanced users that have developed their own personal brands and reach large audiences by producing content within and for YouTube. Webcam technology, the aesthetics of the video blogs, the confessional style and the celebration of the 'bedroom cultures' -an online phenomena born before YouTube- should also be considered when analysing the foundations of these new media subjects. Finally, it should be remembered that the top YouTubers have already gone professional. Nonetheless, according to Burgess and Green, the distinction between professional/amateur is no longer useful to interpret the YouTube practices (2009, pos. 1045).

Carlón (2012) proposed the identification of two levels in his analysis of the use of digital interactive media by a particular subject. The first level, revolving around a socio-technical status, addresses the possibilities of the subject to operate devices in the complex interplay of hypermedia. The second level addresses the activity of the subject in their discursive dimension.

From the moment they create their 'personal profiles', Facebook users become media themselves. And because of this, they generate discourses to communicate their actions and thoughts; they find out what happens, ask their friends questions, organise events, etc. [...] From our perspective, these enunciators are media subjects (Carlón, 2012: 182-183).

YouTubers are not just 'young people uploading videos to the Internet': they create their individuality through those videos. Therefore, YouTubers should also be considered as 'media subjects'. 
In addition to this discursive perspective, YouTubers are situated at the crossroads of the abovementioned tensions and polarizations. According to Burgess and Green

In YouTube new business models and more accessible tools of production are provoking new and uncertain articulations between alternative media and the mainstream, commercial media; and throwing up anxieties about issues of media authority and control (2009, pos. 723$)$.

Just one example of these 'uncertain articulations': a video uploaded by the Spanish YouTuber AuronPlay in October 24, 2014 - Gran Hermano es una estafa / Big Brother is a scam $^{1}$ - reached 1.5 million views and motivated an extraordinary meeting of Mediaset managers - the producers of Big Brother in Spain- to watch AuronPlay's YouTube channel and discuss the online crisis. A second video -La polémica con GHVIP \#GHVIPesBASURA (January 15, 2015)- positioned the hashtag \#GHVipEsBasura (\#BBVipIsGarbage) as a Trending Topic in Spain. Those days Mediaset engaged in a war of tweets with the famous YouTuber, confirming that for old media managers these new subjects are not easy to process and interpret.

\subsection{Semiotics and discursive analytical categories}

In our search for answers to these questions, we applied a set of semiotic and discursive categories to the textual corpus:

- Contact enunciation: In 1960, Jakobson defined six functions of language: referential, poetic, emotive, conative, phatic and metalingual. Inspired by Jakobon's phatic function, the analysis of the bond between the YouTuber-speaker and his/her listeners-viewers is based on five resources: two of them are of a discursive nature (looking into camera, constantly addressing the listener-viewer during the broadcast), while the remaining three are related to the distinctive features the medium has to offer (traffic counters, likes, dislikes and comments counters, articulation with other media and platforms).

- Emotive enunciation: another distinctive attribute of the YouTubers' videos is their emphasized emotive function (Jakobson 1960). If the phatic function is associated with the contact/channel factor, the emotive -also called expressive or affective- 
function relates to the addresser (sender) of the communication act, showing the individual style of each YouTuber.

- Genre: in order to classify YouTubers' videos into different genres, we followed Bakhtin's classic definition of genre. If language is realized in the form of individual concrete utterances, three aspects -thematic content, style, and compositional structure- are 'inseparably linked to the whole of the utterance and are equally determined by the specific nature of the particular sphere of communication'. Even if each separate utterance is individual, each sphere in which language is used 'develops its own relatively stable types of these utterances' (1986: 60). Bakhtin called these relatively stable types of utterances 'genres'.

- Enunciative contract: Verón (1985) proposed the notion of "reading contract" when conceptualizing the relation between newspapers and their readers. Such relation is established between an enunciator (or addresser) and an enunciatee (or addressee). The addressee can then accept or refuse said contract proposed by the addresser. The notion of contract was applied in the study of various media; in this research, we use it to analyse the proposed relation between the YouTuber-enunciator and the audience-enunciatee.

As already indicated, these will be used as pertinent categories within the media ecology theoretical framework that supports the research.

\subsection{Identikit of the Spanish YouTubers}

Even if the present article is not based on a quantitative-oriented research, before addressing the analysis of the Spanish YouTubers' audio-visual discourse it is necessary to briefly describe the real impact of these channels. This description is based on quantitative data collected in July 2015. According to SocialBlade, a website that tracks users performance using YouTube Statistics Tool, the top ten YouTube channels in Spain on July 2, 2015 were the following: 


\begin{tabular}{|l|l|r|r|r|r|}
\hline & \multicolumn{1}{|c|}{ Channel } & $\begin{array}{c}\text { N. of } \\
\text { Subscribers }\end{array}$ & \multicolumn{1}{c|}{$\begin{array}{c}\text { Video } \\
\text { views }\end{array}$} & $\begin{array}{c}\text { Channel } \\
\text { creation date }\end{array}$ & $\begin{array}{c}\text { N. of } \\
\text { videos }\end{array}$ \\
\hline 1 & elrubiusOMG & $12,134,831$ & $2,095,596,500$ & Dec 20th, 2011 & 499 \\
\hline 2 & vegetta777 & $10,091,962$ & $2,932,423,096$ & Mar 2nd, 2008 & 2,337 \\
\hline 3 & Thewillyrex & $7,044,732$ & $1,795,691,873$ & Jan 26th, 2011 & 2,746 \\
\hline 4 & Willyrex & $5,356,783$ & $972,973,085$ & Aug 9th, 2009 & 2,741 \\
\hline 5 & xalexby11 & $4,141,303$ & $544,981,795$ & Jun 1st, 2011 & 2,475 \\
\hline 6 & Mangelrogel & $3,890,352$ & $231,846,964$ & Mar 19th, 2006 & 365 \\
\hline 7 & itowngameplay & $3,546,009$ & $873,551,309$ & Feb 15th, 2012 & 2,916 \\
\hline 8 & sTaXxCraft & $3,178,100$ & $414,009,767$ & May 1st, 2013 & 831 \\
\hline 9 & Luzugames & $3,163,792$ & $346,227,450$ & Nov 27th, 2011 & 1,110 \\
\hline 10 & Zarcortgame & $3,029,239$ & $531,568,508$ & Nov 9th, 2012 & 136 \\
\hline
\end{tabular}

\section{Table 1 - Top 10 Spain YouTube channels (by number of subscribers)}

(July 2nd, 2015 - Source: Socialblade - http://www.socialblade.com)

All of these video channels are managed by young male YouTubers. As it can be seen, they are the kings of the Spanish youtubesphere. For a first analysis of these channels we have used a tool that extracts the basic data of their last published videos (genre, number of comments, likes, average views, video length, etc.). The analysis focused on the 100 most viewed videos created by the YouTubers that manage each channel (Table 2). The most viewed videos were detected using Vidooly - http://vidooly.com.

\begin{tabular}{|c|c|r|r|r|r|c|}
\hline & Channel & \multicolumn{1}{c|}{$\begin{array}{c}\text { Average } \\
\text { comments }\end{array}$} & $\begin{array}{c}\text { Longest and } \\
\text { shortest } \\
\text { videos } \\
\text { (seconds) }\end{array}$ & $\begin{array}{c}\text { Video } \\
\text { average } \\
\text { duration } \\
\text { (seconds) }\end{array}$ & $\begin{array}{c}\text { Average } \\
\text { views }\end{array}$ & $\begin{array}{c}\text { Most } \\
\text { viewed } \\
\text { video }\end{array}$ \\
\hline 1 & elrubiusOMG & 24,987 & $4,447 / 62$ & 519 & $6,859,953$ & $23,613,762$ \\
\hline 2 & vegetta777 & 8,233 & $5,024 / 169$ & 2,004 & $2,940,617$ & $22,950,823$ \\
\hline 3 & thewillyrex & 5,515 & $6,972 / 156$ & 1,566 & $2,061,100$ & $19,547,607$ \\
\hline 4 & Willyrex & 1,125 & $3,011 / / 76$ & 1,120 & 658,274 & $7,291,322$ \\
\hline 5 & xalexby11 & 1,403 & $1,851 / 232$ & 677 & 579,662 & $4,334,868$ \\
\hline 6 & mangelrogel & 3,568 & $10,418 / 39$ & 726 & $1,145,123$ & $4,681,363$ \\
\hline
\end{tabular}




\begin{tabular}{|c|c|r|r|r|r|r|}
\hline 7 & itowngameplay & 26,286 & $7,337 / 126$ & 1,116 & $1,247,411$ & $19,336,610$ \\
\hline 8 & sTaXxCraft & 1,738 & $1,986 / 26$ & 694 & 798,551 & $4,363,130$ \\
\hline 9 & luzugames & 2,574 & $5,964 / 106$ & 1,442 & $1,192,781$ & $4,315,002$ \\
\hline 10 & zarcortgame & 8,324 & $1774 / 71$ & 185 & $3,484,193$ & $29,075,224$ \\
\hline
\end{tabular}

Table 2 - Top 100 viewed videos

(July 2nd, 2015 - Source: Vidooly - http://vidooly.com)

The duration of a Spanish YouTuber video spans from a couple of minutes to almost three hours. Apparently, there is no correlation between the length of the video and the genre: a session of gameplaying may last a few seconds to an hour. In the specific case of elrubiusOMG, he has developed a short format called Games in one minute to introduce different games (Minecraft, World of Warcraft, etc.) $)^{2}$.

Their high number of views -we are talking about millions of asynchronous viewersmakes us wonder when considering the status of these productions: Can we still talk about 'many to many' communication? Or should be consider these practices closer to traditional mass media diffusion? On the other hand, the amount of comments is also representative of the spirit of the web 2.0. Once more, we can see how YouTubers are at the centre of the already mentioned conflicts and tensions regarding the new media ecology.

In regards to genre, when uploading a video to YouTube, the creators must indicate a category for its content (entertainment, comedy, game, etc.). At first sight, it could be said that most of the Spanish YouTubers' video production is divided between gameplaying videos and entertainment. However, after a more detailed observation it is possible to identify different profiles: elrubiusOMG publishes both gameplaying and entertainment videos, while YouTubers like vegetta 777 focus on gameplaying (specially Minecraft) and occasionally personal videos. The same YouTuber may manage two channels: one dedicated to Minecraft (thewillyrex) and a second one for other games and content (willyrex). Other YouTubers like zarcortgame specialise in mixing their passions: videogames and music. It is not extraordinary to find crossover videos featuring two or more YouTubers, for example Luzugames, Willyrex, alexBY11 and MangelRogel playing together. ${ }^{3}$ Obviously, the broad spectrum of genre does not stop at 
gameplaying and entertainment: YouTubers are increasing their specificity and developing niche strategies. We can progressively identify channels featuring make-up, couples, sports, or videos about books.

\section{THE DISCOURSE OF SPANISH YOUTUBERS}

In this section we present an analysis of the YouTubers' production based on semiotic and discursive categories. We carried out an analysis of the top five videos of each YouTuber based on the following categories: highest rating, number of comments and number of views. We will refer to the most representative of the topics covered drawn from a total of 150 videos; at the same time, we will also present some of the semiotic and discursive operations that characterise the YouTubers' videos production grammars. $^{4}$

\subsection{Contact enunciation}

The first visible operation in the YouTubers' audio-visual enunciation is the importance given to contact. Whatever its genre or language used, YouTubers' videos have a marked phatic function (Jakobson 1960) that constantly reaffirms the bond between the YouTuber-speaker and the listeners-viewers. Usually, YouTubers look into camera and address their viewers in their videos (Figure 1).

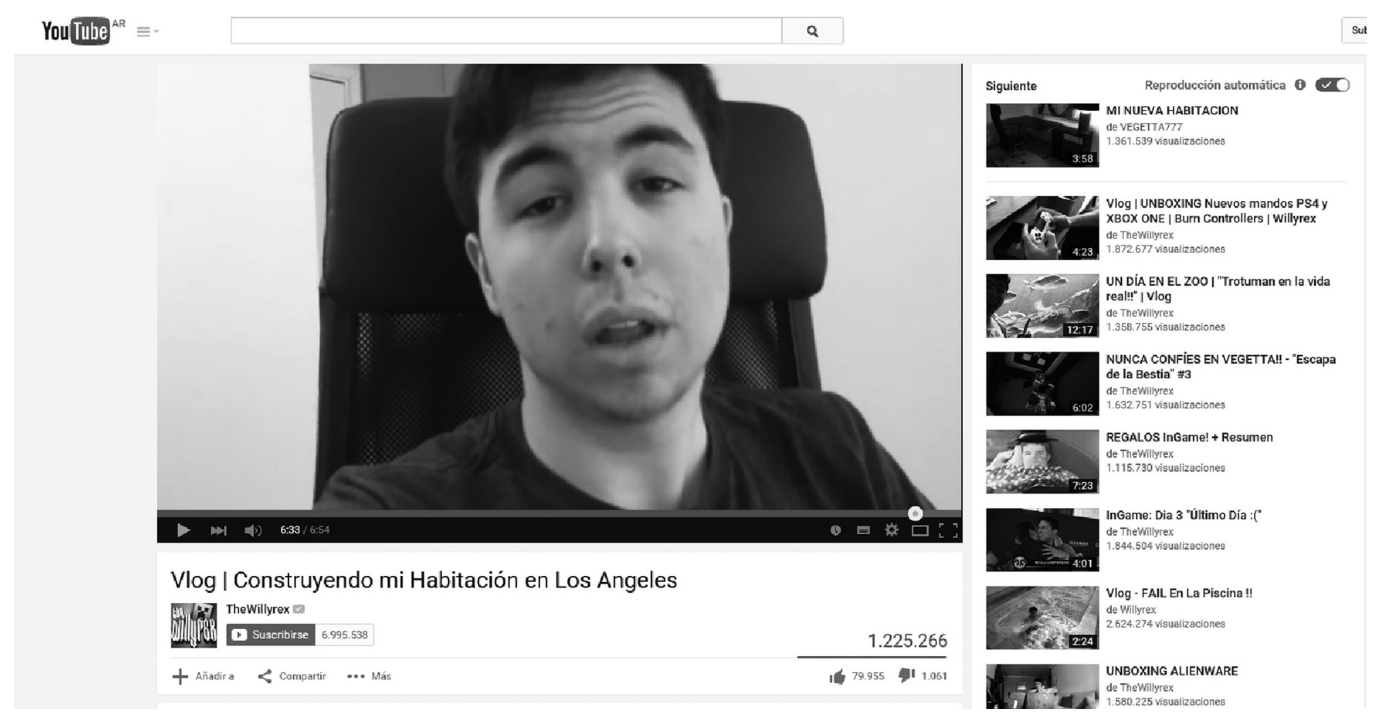

Setting up my room in Los Angeles - TheWillyrex, May 15th, $2014^{5}$

Figure n. 1 
The way the YouTuber-speaker acts is similar to the way TV hosts do, as described by Verón (1983) and Casetti \& Di Chio (1998), when referring to uttered enunciation. By looking into the eyes of the viewers, the enunciative effect gets enhanced, and this creates tension between the public nature of the exchange and interindividual visual contact.

However, even though looking into camera is a distinguishing mark of this kind of videos, YouTubers may not look into the camera for long periods of time or may also record entire videos in which they do not appear on camera. But what rarely happens is them keeping quiet. YouTubers talk tirelessly. Their bodies may stay out of the frame, but their voices are at all times audible, and the way their voices operate can be made equivalent to the way voice-over works in cinema, as analysed by Casetti (1983). The viewer is the addressee of that voice-over, which does not have a fictional nature to it. This kind of discursive production addresses the viewer and invariably revolves around the I-You deixis, with a non-fiction frame to it.

We can affirm so far that, at discursive level, contact enunciation from YouTubers has developed similar resources to television and cinema. However, when focusing on the medium-device level, we see an important difference between YouTubers' videos and traditional media, that points at the specific nature of this kind of broadcasting. YouTube and its convergence with other media, such as Twitter, promote the viewer's individuation. As the following image shows, the interface presents a views counter and a subscriber counter (Figure 2).

\section{VEGETTA777 RAP | Zarcort}

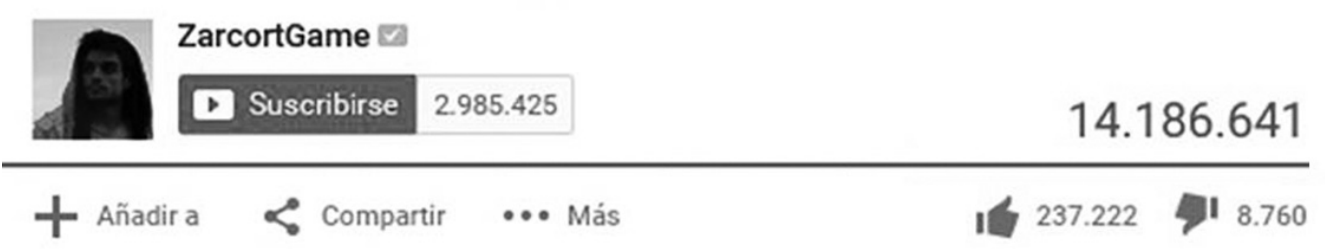

Publicado el 7 dic. 2013

Subscriber counter, view counter, like and dislike counter - ZarcortGame, December 13th, $2013^{6}$

Figure n. 2 
Thanks to the counters, each view and subscriber gains an individual value, while it increases the number shown on screen. This way, a particular viewer is not equivalent to another particular viewer, because each one leaves an individuation mark on a publicaccess interface. Nothing like this happens with traditional broadcasting television. The device used to watch television does not come with any indicator that allows the viewer to know how many people are watching the show, or how many people have watched it so far and how he/she is adding to this number. Traditional television creates undifferentiated watching (with the exception of shows that include tweets or WhatsApp messages on screen, increasingly appearing on TV).

Let us take a look at the following example so we can assess the nature of this particular individuation in YouTubers' videos. During a live broadcast, elrubiusOMG announces he has $8,999,523$ subscribers and challenges the viewers to reach 9 million at that precise moment. If they manage to make it, he promises them a surprise. After twelve minutes, during which he continues to talk and to anxiously look at the subscriber counter, elrubius $O M G$ reaches his objective and keeps his promise: he puts a Minecraft box over his head and starts doing a dance (Figure 3).

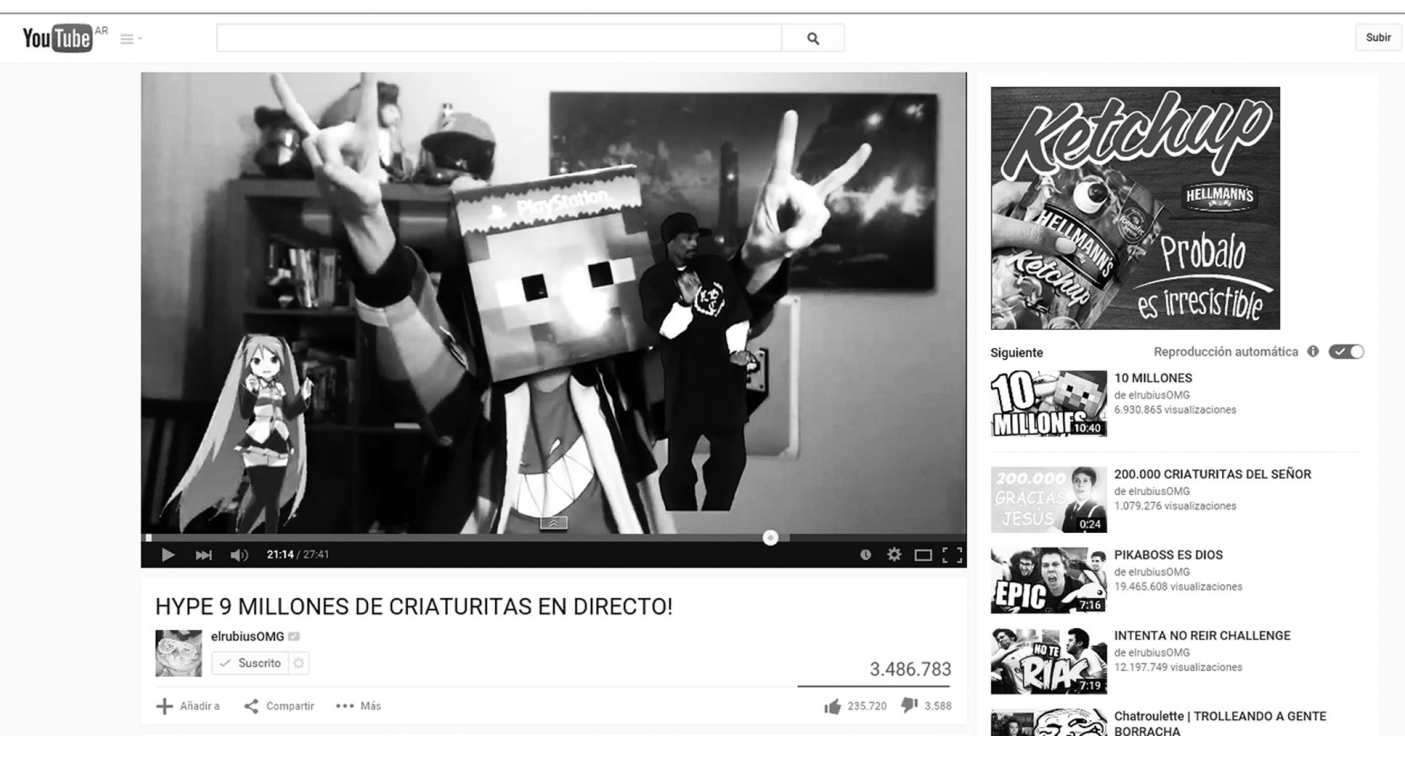

I Hyped 9 Million Creatures Live - elrubiusOMG, November 19th, $2014^{7}$

Figure n. 3

The reason for the success of the broadcast is that it was based on individualized contact. During this broadcast, both actions of subscribing and getting subscribers met at a joint action, made visible in the counter numbers. 
Another resource enhancing viewer's individuation is the interaction the interface allows. In it we find a like and dislike counter and a public area in which viewers, individualized by nickname, can leave their comments for the YouTuber to answer. The possibility of feedback transforms viewers into addresser media subjects. Feedback is strengthened and expanded by the articulation between different hypermedia accounts, such as Twitter, Facebook and Instagram. The YouTuber receives many viewers' messages via different media and frequently answers to those in the videos.

\subsection{Emotive enunciation}

Another distinctive feature found at YouTubers' videos is their strong emotive function (Jakobson 1960). Their enunciation focuses on the feelings of the YouTubers as diegetic speakers. Their gestures, tones of voice and statements tell us about how they feel when playing a certain video game, or what they do to have fun with their friends and the emotions they feel when attending gaming conventions. They also show their reactions on video when opening presents sent by their fans. The emotive function is present even in those videos in which the objective is to give information. In his Top 7 most expected games -by me- $^{8}$ video, alexBY11 announces the names of videogames about to be released, but the selection and rank order in which he presents them is arranged merely according to his taste and the expectation that certain game launchings have created in him, as the next fragment shows:

Today, I am bringing you the Top 10 games I am personally most looking forward to in 2014. You can leave your opinions in the comment section. Without further ado, let's start. At number 10, we have Dying Light. For those of you who don't know it, this game is similar to Dead Island in the sense that it is played from a 1 st person perspective. One has to survive in a world with too many zombies to keep count, but the original touch this game has, which is also the reason why I like it and I chose it as one of my Top 10 favourites, is that the zombie storyline is combined with parkour gaming [...] This is something that 1 st person zombie games lacked, in my opinion. And it is the reason why I selected it to be in this Top 10 . 
The emotive function highlights the individual style of each YouTuber. As their production has a non-institutional nature, this attribute is reinforced. The YouTuberspeaker is not equivalent, in this sense, to the television host because, even though television hosts display their particular personality, the show's enunciation is polyphonic because of the presence of the other actors from that channel (technicians, director, cameramen, etc.). YouTubers, on the other hand, even when they mention or show who is filming them, take on the role of responsible speakers of their videos and their videos' style. As pointed out above, we could say that contact enunciation that puts emphasis on emotive function proposes an exchange scene in which the YouTuberspeaker and the viewer are conceived as individualities.

\subsection{Genre}

Following Bakhtin's classic definition of genre -productions that have certain similarities in their thematic content, verbal style and composition-, YouTubers' videos can be grouped into six major genre.

- Gameplay videos: Screencast in which the YouTuber plays alone or with others online. Videos of this kind usually have had none to nearly none editing. It is common to see a tiny superimposed image that shows the YouTuber playing (Figure 4).

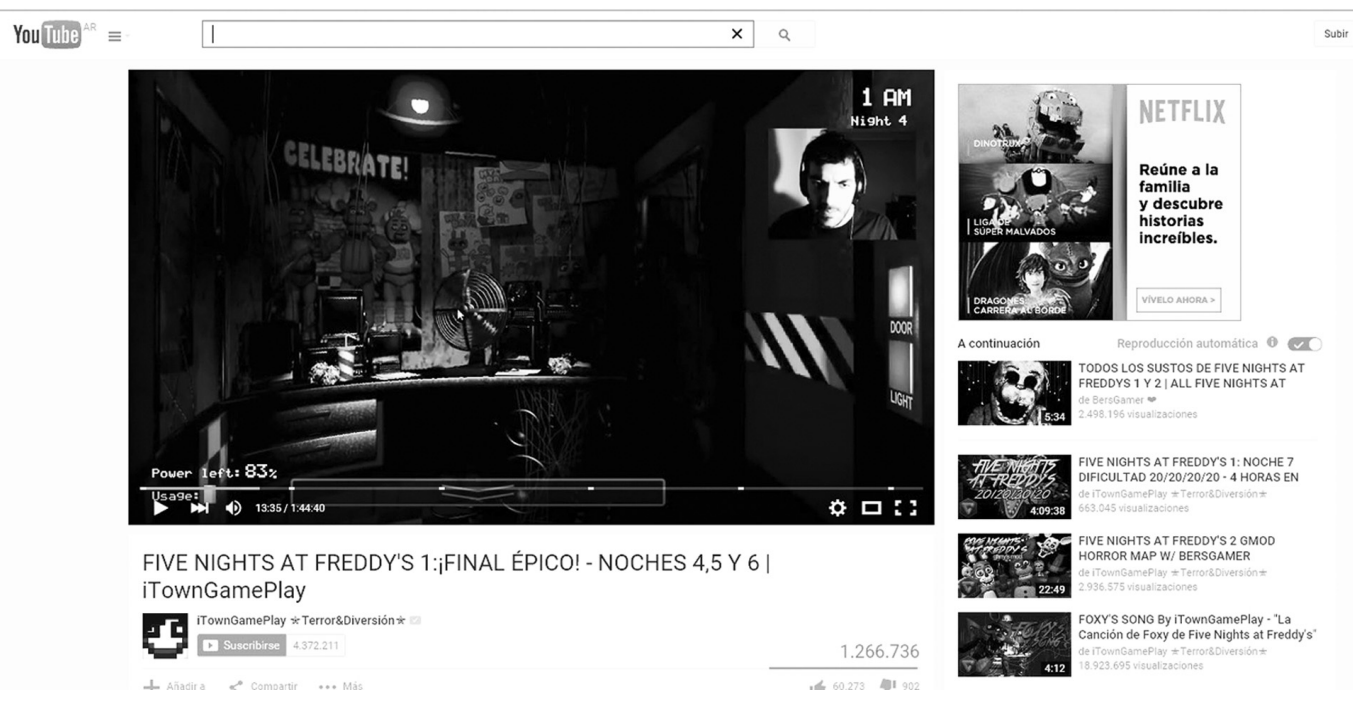

Five nights at Freddy's 1: epic finale! - nights 4, 5 and 6 | iTownGamePlay iTownGamePlay, February 28th, $2015^{9}$ 
Figure n. 4

Gameplay videos conform a type of narrative genre that originated in the users' practices. They tend to develop in an episodic fashion, and the story and actions in the videos advance as the gaming moves forward. According to the type of broadcast (live or pre-recorded), they construct two different types of views: live television-like view and cinema-like view (Carlón, 2006). These videos also use the possibility of feedback that the device offers. This type of narrative revolves around showing the vicissitudes the YouTuber goes through inside the game's fictional universe. The storytelling is built upon the avatar's actions and the constant remarks made about the game and the feelings the YouTuber is experiencing. Its antecedent is video game reviews, a genre previous to the existence of YouTube, consisting on similar statements in the first person and the story of the speaker's gaming experience (Scolari and Fraticelli, 2013). Within the analysed corpus, gameplay videos conform the main genre with the most views and the highest rankings.

- Tutorials: These videos walk the viewer through the procedures needed to carry out certain activities. In the case of the analysed YouTubers' videos, tutorials explain how to do $\operatorname{mods}^{10}$ or how to overcome certain videogame's difficulties. The enunciation is educational; they are usually pre-recorded videos that can also work as answers to the fans' request to the YouTuber to explain their game tactics. An example can be seen in Five Night's at Freddy's 3 Good Finale, in which iTownGamePlay explains the best way to finish the game ${ }^{11}$.

- Videoclips: Pre-recorded music videos, dedicated mainly to videogames. Three main procedures appear in this kind of video: added music (not written by the YouTuber) to an edited gameplaying session/s; mashing-up a popular song with images from videogame characters, whether the images are taken from old rounds of games or from an original animation ${ }^{12}$; and the creation of an original music theme with the topic of videogames. Zarcortgame is one of the rapper-YouTubers that specializes in this kind of productions ${ }^{13}$.

- Interviews: In these videos, YouTubers answer their fans' questions live, which send them via YouTube and Twitter. Usually, their questions are about the YouTuber's private life and future plans. In the analysed corpus, videos from this genre present the highest number of comments ${ }^{14}$. 
- Vlogs: These videos are about life experiences (not related to videogames). In them, the YouTuber looks into camera and presents a certain subject. Then, a narration begins that has him as the lead character. It can be about a trip to another city ${ }^{15}$, a friend's visit or a house-warming party ${ }^{16}$, etc. The universe in reference in the story is independent from videogaming. The viewer is constantly addressed in a nonfictional way. Enunciation in this kind of video creates a double speaker. One is diegetic -the YouTuber-, since he is the subject in action (frequently, holding the camera as well). The extra-diegetic speaker is created during editing. Added music, collage, pastiche, graphic add-ons and zoom affect the storytelling and ends the effect of transparency the above genres hold. The added speaker makes comments and jokes and frequently makes a fool out of the YouTuber.

- Television-like videos: In this kind of videos the main form of enunciation comes from television. In them the YouTuber can be seen performing a hidden-camera joke $^{17}$, or talking about videogame conventions and releases as well as doing videogame reviews and critiques ${ }^{18}$. Even when this kind of video has a primarily contact-oriented and emotive enunciation, the YouTuber acts in them as a television reporter. Alongside vlogs, videos within this genre are highly edited and produce a double speaker as well.

\subsection{Two enunciative contracts: ludic-professional and ludic-neophyte}

Two enunciative contracts - that is, two different ways of making videos and addressing the viewer- emerged from the analysed textual corpus. We will define the first contract as ludic-professional. In this case the YouTuber focuses the content of their video on videogames and gameplaying. Their prevailing genres are gameplay videos, tutorials and videoclips. Although emotive enunciation is also present in this kind of contract, the player's emotions get diminished by the supremacy of videogame playing. Contact enunciation is built upon an educational purpose or as a response from the YouTubers to their fans' demands asking him to play a certain videogame, to show them tricks or to teach them how to build a certain mod. When the YouTuber enunciator assumes a teaching position, an asymmetrical connection is established with the audience. However, this asymmetry is attenuated because the enunciatee knows about video games and the gaming world. Itowngameplay's videos ${ }^{19}$ holds the most representative examples of this type of enunciative contract. 
We define the second enunciative contract as ludic-neophyte. As in the previous case, the enunciator is also a gamer, but the videos are not limited to the videogaming universe as they also include vlogs and television-like videos. Gameplay videos still represent the dominant genre, but the enunciator assumes in this case the role of a noobie that is learning how to play the game as he/she plays it. The relationship with his/her enunciatee is built upon the YouTuber's dual positioning: the enunciatee becomes a symmetrical accomplice, with which the YouTuber shares knowledge and with whom he learns about the vicissitudes of the game, and also a lower asymmetric one, since the YouTuber is constructed as a derided player because of his/her unsuccessful playing, his/her outbursts of rage and terror provoked by the game, etc. Emotive enunciation prevails in this kind of production and justifies the contact. The neophyte player does not teach nor informs: the YouTuber rather amuses the viewers and becomes himself the funny object of his own enunciation. elrubiusOMG is the YouTuber who most clearly assumes this enunciation proposal. ${ }^{20}$

Both proposals create as well different viewers. While the ludic-professional YouTuber addresses a segment of viewers interested in videogames, the ludic-neophyte YouTuber builds a larger audience that prioritizes individual emotive contact rather than a particular subject. This difference in style might possibly be the reason why elrubiusOMG counts over 12 million subscribers while Itowngameplay counts a little over 3 million.

\section{ADAPTATION AND SIMULATION}

In this section we present an analysis of Yutubers, a TV program produced by Comedy Central that remediates the aesthetics and grammar of the YouTubers' channels.

In February 2015 TV channel Comedy Central premiered a show called Yutubers ${ }^{21}$ dedicated to 'all the latest things online'. Its hostess is the young actress and singer Angi Fernandez and she is joined by some of the most famous Spanish YouTubers. The show has different sections that focus on YouTube, Instagram, Facebook and Twitter productions like 'Who the hell lives there?' ('¿Quién demonios vive ahí?’), that presents a YouTuber's home, or 'Today's guest' ('El invitado de hoy'), in which the hostess interviews a well-known prosumer. 
In a time when old media has to adapt to the new media's ecosystem in order to survive, this show represents a good opportunity to analyse the way in which television takes over a successful production from its most dangerous competitor: YouTube. We are now going to focus on some of the most significant traits from YouTubers' videos this show replicates and then analyse the way it interprets them.

Yutubers is a pre-recorded show. Its editing has the following characteristics:

- Accelerated montage

- Superimposing of images conforming collage and comic pastiche (Figure 5)

- Frequent hand-held-camera shots

- Superimposing of screen-captions simulating hypertextual windows

- Still-camera shots imitating webcam takes

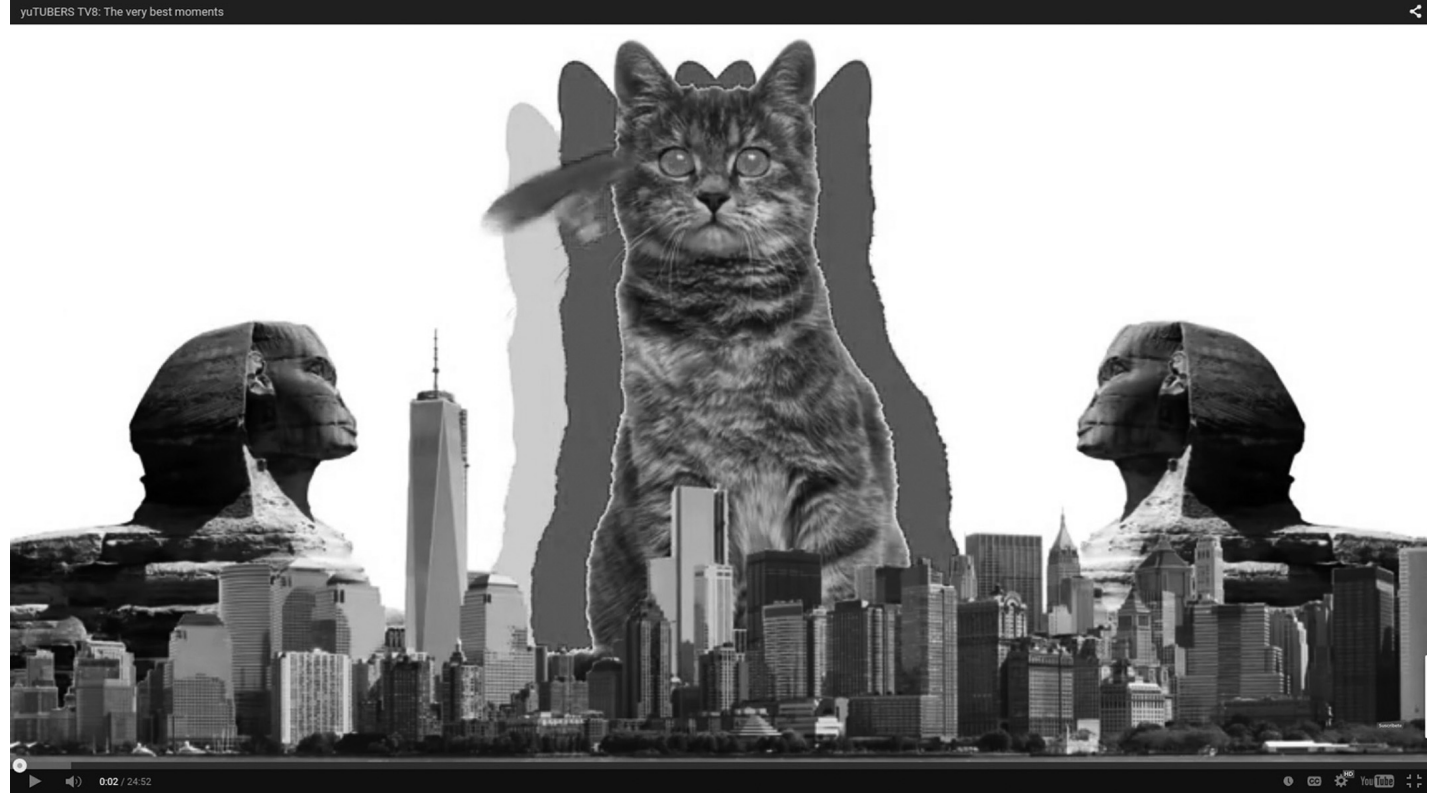

Collage in Yutubers' opening ${ }^{22}$

Figure n. 5

When studying the first three operations we can see how the show assumes the kind of editing used in the most television-like YouTubers' videos: vlogs, and those other we call, precisely, television-like videos. The kind of editing used in gameplay videos, tutorial and videoclip videos -the prevailing YouTubers' productions- is not used in this show. 
Cornered by zapping, Yutubers also adopts a fast-paced edition in order to capture the audience's attention. This strategy has been used in television since before the existence of YouTube.

The inclusion of screen captions simulating hypertextual windows is, on the other hand, a truly representative operation of the YouTuber aesthetics, even though the content presented in the Yutubers show differs from the one in YouTubers' videos. In those, these screen captions usually show YouTubers playing videogames. In the show, the screen captions present images that assimilate to the photo, drawing and animation pastiche superimposed on screen, or present YouTubers looking into camera and acting funny (Figure 6).

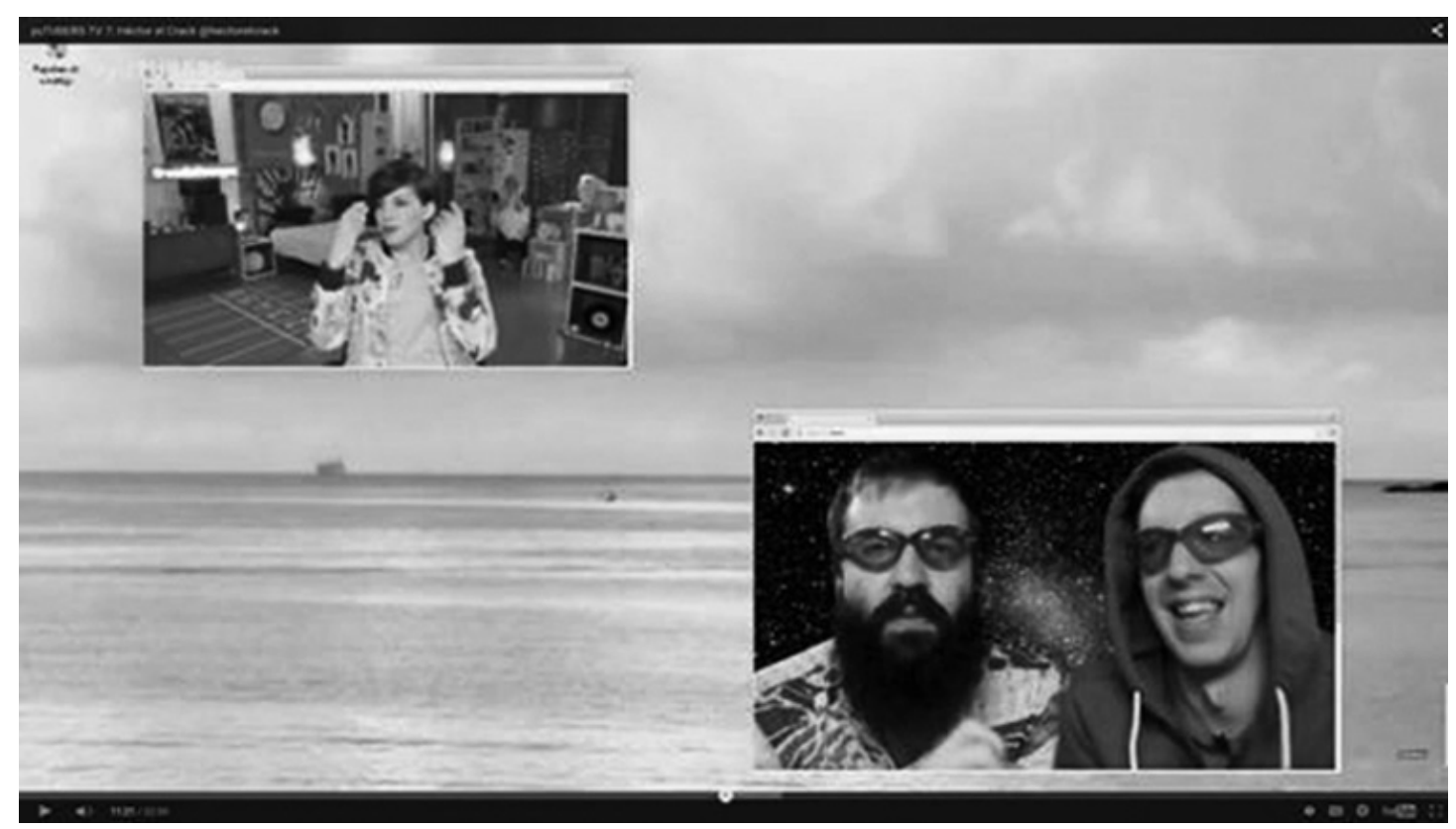

Screens simulating hypertextual windows in Yutubers ${ }^{23}$

Figure n. 6

The last operation that the show Youtubers carries out in an attempt to imitate the YouTubers' productions is the simulation of webcam shots. This is achieved by producing a low quality image along with shots taken by a camera positioned on the desk where the host is located (Figure 7). Such a shot is continuously combined with regular studio camera shots. 


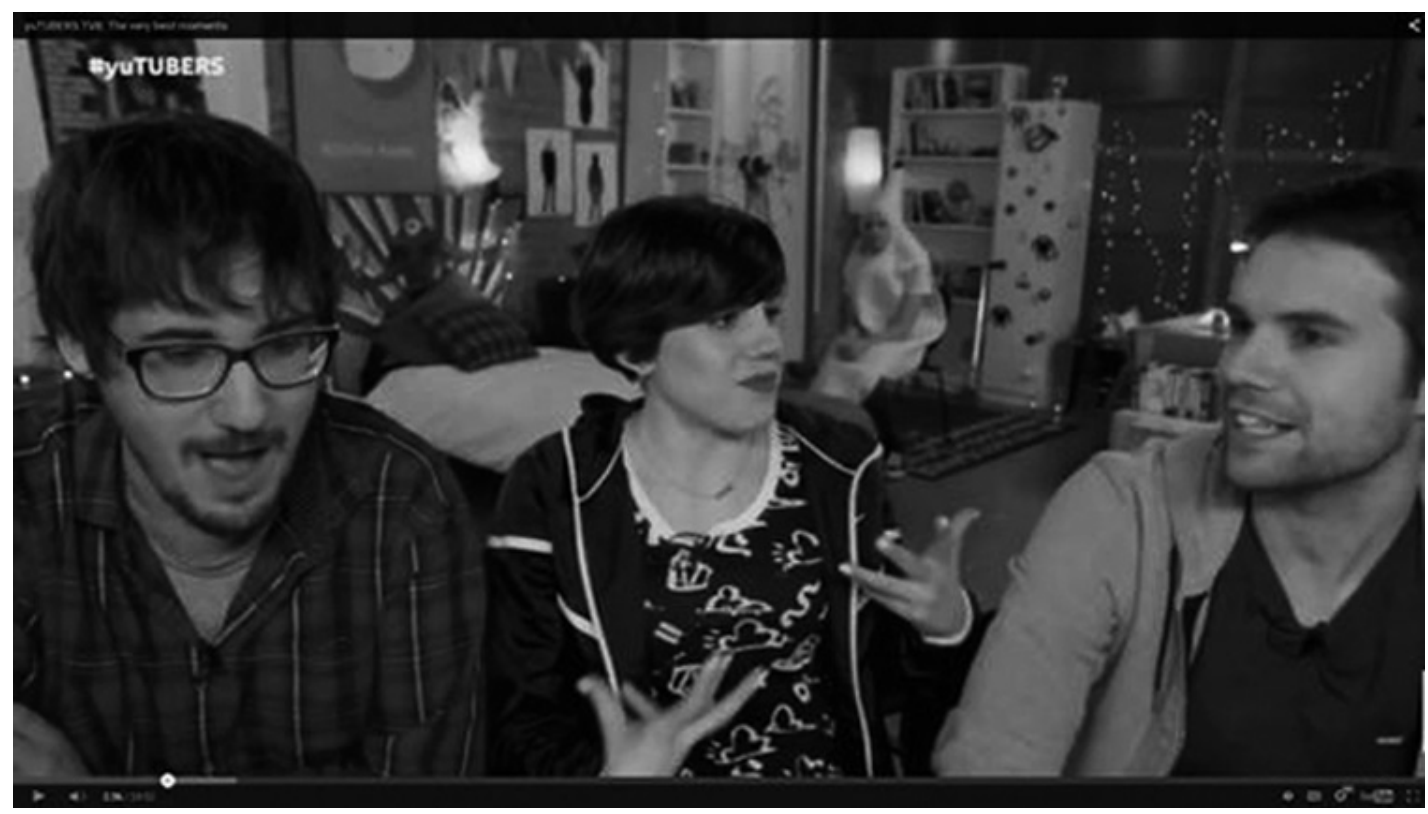

Webcam-like shot in Yutubers ${ }^{24}$

Figure n. 7

As it has been described, Yutubers is about Spanish YouTubers, and five of the most popular ones are regular appearances in the show. Nonetheless, their partaking does not mean that the way they appear in the show is the same as they do in their videos. Their character as gamers and music and videogame enjoyers gets weaken in the show by the accentuated portrayal of a young, prosumer, neophyte and funny person. Even when the show uses the way YouTubers portray themselves in their channels, the show's enunciation constructs YouTubers as subjects of utterance and not of enunciation.

Yutubers broadcasts guest YouTubers' videos. The show's hostess also interviews them and puts them in funny situations. YouTubers in the show act as funny television host and reporters' apprentices that mess up constantly. As the show's guests, they are subjects to an editing process that highlights their mistakes and witticism, and in this way portrays them as funny objects. The show's editing as well as the voice-over summarizing the content and the exhibition of technological media (microphones, cameras, etc.) in the same way 'neotelevision' does it (Eco, 1985) are the utterance's creators. The prosumer nature that defines the YouTuber's character is restricted, as the YouTuber does not reach his/her state as subject of enunciation. The limits that television faces when trying to take over the YouTubers' production gets in this way exposed. Television may adopt several of the YouTubers' video characteristics, but the 
enunciative effect brought about as a result of an individual being responsible for an utterance is out of its reach, because in this case the speaker is not an individual but an institution.

\section{CONCLUSIONS}

The analysis of the enunciation strategies and enunciative contracts of the top Spanish YouTubers shows that the viewer's individuation is a distinctive trait in their production. If we focus on contact enunciation, the way the YouTuber-speaker operates is similar to the way TV hosts do. Even if they do not look into the camera for long periods of time, they move and talk tirelessly, addressing the viewer by means of that voice-over. On the other hand, when the analysis focuses on emotive enunciation, it highlights the individual style of each YouTuber. The non-institutional nature of the YouTuber productions is reinforced. In this sense, the YouTuber-speaker strategy is not equivalent to the traditional television host.

The success of YouTubers seems to have its basis in the emphasis given to individualized contact. This kind of contact generates an individual who assumes the production of the videos, and at the same time an active viewer that leaves his/her mark on the interface and actively participates by commenting, expressing their likes and dislikes, subscribing to the channel and contacting the YouTuber via other media such as Twitter.

During the course of this research two types of enunciative contracts in the Spanish YouTubers proposal have been detected: the ludic-professional, mostly focused on videogames and gameplaying, and the ludic-neophyte, that goes beyond the videogaming universe in order to include vlogs and television-like videos. In the first case, the production favours gameplay videos and addresses a public demanding information from the gaming universe; in the second one, the videos appeal to a wider audience in a more emotive way.

Regarding genre in the top Spanish YouTubers' production, six typologies were identified: gameplay videos, tutorials, videoclips, interviews, vlogs and television-like videos. This taxonomy, based on semio-discursive criteria, proposes a first output that could be expanded/confronted with those from other similar studies. Genre analysis is 
always a critical issue that, in the specific case of YouTube, sees its complexity increased because of the great number of content and hybridizations between the different genre.

Even if the objective of this research was to analyse the main Spanish Youtubers' productions, the next step in this line of investigation should be the development of a comparative analysis to identify the main differences and similarities between YouTubers from different countries and regions. Questions like "Is there a common YouTuber style?" or "are there any particular national specificities in their discourse?" might be central to a broader research program. For example, in countries like Mexico 'booktubers' are a smash hit (Tomasena, 2016) and (meta)videos about YouTubers are also very popular. Other issues like the emergence of new audio-visual formats or genres present thought-provoking challenges to media researchers. In this context, future researchers could confirm if YouTubers are reproducing (or not) the same evolving path that broadcast television went through from traditional generalist channels (ABC, NBC, CBS) to specific or thematic channels (MTV, CNN, etc.).

In the specific case of Yutubers, the analysis of this TV show confirms how an 'old' media like television is adapting to the new conditions of the media ecology. The show incorporates the YouTubers' aesthetic, for instance, by imitating the accelerated edition, the hand-held camera shots or images collages typical of vlogs and what we refer to as 'television genre' videos from YouTubers. However, such a simulation is limited by the logic of television as an institution. Edited footage showing gameplay and tutorials, for example, does not make it to the TV show. Gameplay videos from YouTubers often base their storyline on failed attempts to overcome the obstacles of the game, and this causes these videos to show a high amount of repetition. Tutorials, on the other hand, have a slow pace that is typical of an educational description. Both procedures go against the fast edition neotelevision aims at in the attempt to capture an audience that is prone to zapping. Another significant limit in the simulation is that the TV show cannot incorporate the enunciative effect of having an individual being responsible for an utterance. The guest YouTubers in the TV show are subjects of utterance and not of enunciation. Individual enunciation, on which the relationship of the YouTuber with his/her viewers is built upon, is beyond the reach of the TV show because the latter is a product of a broadcasting institution. 
The methodological framework presented in this article -a combination of semiotic and discursive analytical categories within a media ecology approach- is a useful tool for the analysis of the emergence of new media subjects and the adaptation of old media to a new context characterised by a deep transformation of the whole media system. This approach could be extended to the study of other emergent subjects -i.e. Instagrammers or other enunciators from the new media- and adaptation processes - i.e. the remediation of webpages by many contemporary newspapers-. The complexity of these and other media transformation processes is so high that a single approach is not enough for dealing with them. Therefore, coming up with a battery of combined analytical tools turns out to be a beneficial path for this kind of analysis.

This project has received funding from the European Union's Horizon 2020 research and innovation programme under grant agreement No 645238 


\section{REFERENCES}

Aranda D, Sánchez-Navarro J and Roig T (2013) Fanáticos. La cultura fan. Barcelona: Editorial UOC

Bakhtin M (1986) Speech Genres \& Other Late Essays. Austin, TX: University of Texas Press.

Bolter D and Grusin R (1999) Remediation: Understanding New Media. Cambridge (MA): MIT Press.

Burgess J (2014) From 'Broadcast yourself' to 'Follow your interests': Making over social media. International Journal of Cultural Studies 18(3): 281-285. DOI: $10.1177 / 1367877913513684$

Burgess J and Green J (2009) YouTube: Online Video and Participatory Culture. Cambridge, MA: Polite Press (Kindle edition).

Carlón M (2006) De lo cinematográfico a lo televisivo. Buenos Aires: La Crujía.

Carlón M (2012) En el ojo de la convergencia. Los discursos de los usuarios de Facebook durante la transmisión televisiva de la votación de la ley de matrimonio igualitario. In: Carlón M and Fausto Neto A (eds) Las Políticas de los Internautas. Buenos Aires: La Crujía, pp. 173-194.

Carlón M (2013) Contrato fundacional, poder y mediatización: noticias desde el frente sobre la invasión a Youtube, el campamento de los bárbaros. MATRIZes 7(1): 107-126. Available at: http://www.revistas.usp.br/matrizes/article/viewFile/56648/59668 (accessed 15 May 2016)

Casetti F (1983) Les yeux dans les yeux. Communications. Enonciation et cinéma 38: 72-97.

Casetti F and Di Chio F (1998) Analisi della televisione. Strumenti, metodi e pratiche di ricerca. Milan, Italy: Bompiani. 
Cunningham S and Silver J (2013) Screen Distribution and the New King Kongs of the Online World. New York, NY: Palgrave Pilot.

Cunningham S, Craig D and Silver J (2016). YouTube, multichannel networks and the accelerated evolution of the new screen ecology. Convergence. DOI: $10.1177 / 1354856516641620$.

Eco U (1985) TV: La transparenza perduta. In: Sette anni di desiderio. Milan, Italy: Bompiani, pp. 308-322.

Gal S (2002) A Semiotics of the Public/Private Distinction. differences: A Journal of Feminist Cultural Studies 13(1): 77-95.

Hellekson K and Busse K (eds.)(2006) Fan Fiction and Fan Communities in the Age of the Internet: New essays. Jefferson, NC: McFarland.

Houle D (2007) The Shift Age. Chicago, IL: Sourcebooks

Innis H (2003) The Bias of Communication. Toronto, Canada: University of Toronto Press (orig. ed. 1951).

Jakobson R (1960) Closing Statement: Linguistics and Poetics. In: Sebeok T (ed) Style in Language. Cambridge, MA: MIT Press, pp. 350-377.

Jenkins H (1992) Textual poachers: television fans and participatory culture. London: Routledge.

Jenkins H (2006a) Convergence Culture: Where Old and New Media Collide. New York, NY: NYU Press.

Jenkins H (2006b) Fans, bloggers, and gamers: Exploring participatory culture. New York: New York University Press.

Jenkins H, Ito M and boyd d (2016) Participatory Culture in a Networked Era: A Conversation on Youth, Learning, Commerce, and Politics. Cambridge, UK: Polite Press. 
Kompare D (2002) Flow To Files: Conceiving 21st Century Media. In: Media In Transition 2 Conference, Cambridge, MA, 11 May 2002. Available at: http://cmsw.mit.edu/mit2/Abstracts/DerekKompare.pdf (accessed 15 May 2016)

Lange P (2008) Publicly Private and Privately Public: Social Networking on YouTube. Journal of Computer-Mediated Communication 13(1): 361-380.

DOI: $10.1111 /$ j.1083-6101.2007.00400.x

Lange P (2011) Video-mediated nostalgia and the aesthetics of technical competencies. Visual Communication 10: 25-44.

Lobato R (2016) The cultural logic of digital intermediaries: YouTube multichannel networks. Convergence. DOI: 10.1177/1354856516641628.

Manovich L (2009) The Practice of Everyday (Media) Life: From Mass Consumption to Mass Cultural Production? Critical Inquiry 35(2): 319-331.

McLuhan M (2003) Understanding Media: The Extensions of Man. New York, NY: McGraw-Hill (orig. ed. 1964).

Scolari CA (2012) Media Ecology: Exploring the Metaphor to Expand the Theory. Communication Theory 22(2): 204-225. doi: 10.1111/j.14682885.2012.01404.x

Scolari CA (2013) Media Evolution: Emergence, Dominance, Survival and Extinction in the Media Ecology. International Journal of Communication 7: 1418-1441. doi: $1932-8036 / 20130005$

Scolari CA (2009) The Grammar of Hypertelevision An identikit of the convergence age television (Or how television is simulating new interactive media). Journal of Visual Literacy 28(1): 28-49. doi: 10.1080/23796529.2009.11674658

Scolari CA and Fraticelli D (2013) Enunciando la interacción: las reseñas de videojuegos. In: Scolari CA (ed.) Homo Videoludens 2.0. De Pacman a la gamification. Barcelona: Laboratori de Mitjans Interactius / Universitat de Barcelona - Santiago de Chile: Universidad Mayor, pp. 205-222. 
Tomasena JM (2016) Los videoblogueros literarios (booktubers): entre la cultura participativa y la cultura de la conectividad. Master's thesis, Department of Communication. Barcelona: Universitat Pompeu Fabra. Available at: http://hdl.handle.net/10230/27963

Van Dijck J (2013) The Culture of Connectivity: A Critical History of Social Media. Oxford, UK: Oxford University Press.

Verón E (1983) Il est là, je le vois, il me parle. Communications. Enonciation et cinéma 38: 27-49.

Verón E (1985) Contrat de Lecture, Une Nouvelle Méthode Pour les Etudes de Positionnement Prend En Charge Les Médias. In: Les Médias: Experiences, recherches actuelles, aplications. Paris, France: IREP (Institut de Recherches et d'Etudes Publicitaires).

Verón E (2004) Fragmentos de un tejido. Barcelona, Spain: Gedisa.

Vonderau P (2016) The video bubble: Multichannel networks and the transformation of YouTube. Convergence 22(3). Epub ahead of print August 2016. DOI: $10.1177 / 135485651664188$

Williams R (1974) Television: Technology and Cultural Form. London: Fontana. 


\section{Author biographies}

Carlos A Scolari is associate professor at the Department of Communication of the Universitat Pompeu Fabra - Barcelona. His research interests include media ecology/evolution, transmedia storytelling and inter- active digital communication. He's the PI of the TRANSLITERACY / Horizon 2020 - Research and Innovation action.

Damián Fraticelli is lecturer of Semiotic and Media Studies at the Universidad de Buenos Aires (Argentina). His research interests include the contemporary production of humour, the interactivity between broadcast and networking media and the emergence of new enunciators at Internet. 


\section{NOTES}

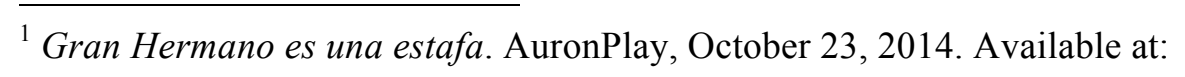

https://www.youtube.com/watch?v=9JbAua7oLJw

${ }^{2}$ Juegos en un minuto. Available at:

https://www.youtube.com/playlist?list=PL438YT18SZFDdtGWYgGWA77N81YeDsqkg

${ }^{3}$ Detrás de las cámaras!!! Con Willyrex, AlexBY y MangelRogel, Luzurgames, July 23, 2013.

Available at: https://www.youtube.com/watch?v=1t55mniAlD0

${ }^{4} \mathrm{We}$ understand the production grammar as the set of rules that describe discursive generation operations (Verón 2004: 41).

${ }^{5}$ Construyendo mi habitación en Los Ángeles, TheWillyrex, May 15, 2014. Available at: https://www.youtube.com/watch?v=OwEM8IF5ABI\#t=392

${ }^{6}$ Subscriber counter, view counter, like and dislike counter, ZarcortGame, December 13, 2013. Available at: https://www.youtube.com/watch?v=n4lvn4Y9Or0

${ }^{7}$ Hypie 9 Millones de Criaturitas en Directo, elrubiusOMG, November 19, 2014. Available at: https://www.youtube.com/watch?v=tG1Z52NEdCY

${ }^{8}$ Top 7 mis juegos más esperados -por mí, AlexBY11, January 2, 2014. Available at:

https://www.youtube.com/watch?v=14vRTkifvWg

${ }^{9}$ Five nights at Freddy's 1: ifinal épico! - noches 4, 5 y 6, iTownGamePlay, February 28, 2015. Available at:

https://www.youtube.com $/ v /$ LezrCUYir5o?version $=3 \& f=$ videos $\&$ app $=$ youtube gdata

${ }^{10}$ Optional add-on to a game that alters aspects of the original, usually created by the users.

These adjustments may range from simple changes on the characters to graphic improvements to complete recreation of settings, or games that are total aliens to their original designs (according to Gamer Dic, available at: http://www.gamerdic.es).

${ }^{11}$ Final bueno de Five Nights at Freddy's 3. Available at:

https://www.youtube.com/watch? $\mathrm{v}=\mathrm{KBJ} 9 \mathrm{fn} \times 2 \mathrm{aNs} \# \mathrm{t}=24$

${ }^{12}$ Final Bueno De Five Nights At Freddy's 3 | Tutorial - (Easter Eggs\&Mini Games) Fnaf3, Itowngameplay, March 5, 2015. Available at:

https://www.youtube.com/watch?t=115\&v=PA_jCeeDaag

${ }^{13}$ Minecraft - "Miners in the Sun" (Parodia de "Lovers of the Sun" de David Guetta)|Video

Oficial, Zarcort, December 7, 2013. Available at:

https://www.youtube.com/watch?v=n4lvn4Y9Or0

${ }^{14}$ Hangout, VEGETTA777, January 17, 2015. Available at:

https://www.youtube.com/watch?v=tJTXfWEbfl4

${ }^{15}$ Tres retards en Londres, elrubiusOMG, March 17, 2014. Available at: https://www.youtube.com/watch?v=yjTywff2PnY 
${ }^{16}$ Me voy a vivir solo, AlexBY11, February 11, 2015. Available at:

https://www.youtube.com/watch?v=3fBKcw1VEwo

${ }^{17}$ Incomodando a la gente en la pizzería. Cámara oculta, elrubiusOMG, May 1, 2014. Available at: https://www.youtube.com/watch?v=fD f1XcKCuw

${ }^{18}$ Último día de InGameExperience!!!, LuzuGames, May 5, 2014. Available at: https://www.youtube.com/watch?v=Gh9H8MjNOtQ\& feature=player embedded ${ }^{19}$ Itowngameplay. Available at: https://www.youtube.com/user/iTownGamePlay ${ }^{20}$ elrubiusOMG. Available at: https://www.youtube.com/user/elrubiusOMG

${ }^{21}$ Yutubers. Available at: http://www.comedycentral.es/yutubers/

${ }^{22}$ Collage in Yutubers' opening. Available at: http://www.comedycentral.es/yutubers/

${ }^{23}$ Screens simulating hypertextual windows in Yutubers. Available at:

http://www.comedycentral.es/yutubers/?video=WAcwY4JOS7Q

${ }^{24}$ Webcam-like shot in Yutubers. Available at:

http://www.comedycentral.es/yutubers/videos/?video=1199656 